\title{
OPEN Retraction Note: Modified box dimension and average weighted receiving time on the weighted fractal networks
}

\author{
Meifeng Dai, Yanqiu Sun, Shuxiang Shao, Lifeng Xi \& Weiyi Su \\ Retraction of: Scientific Reports https://doi.org/10.1038/srep18210, published online 15 December 2015
}

The Editors have retracted this Article because significant portions of the text and equations were taken from Roland Molontay's BSc thesis without attribution ${ }^{1}$.

The following parts of the paper are copied verbatim or are adapted from those appearing in the thesis: the definition of $\mathrm{dB}$ and preceding and subsequent sentences; Definition 3.2; Proof of Lemma 3.4; Lemma 3.5; Proof of Lemma 3.5; Lemma 3.6; Proof of Lemma 3.6; Equation 6; Lemma 3.7; Proof of Lemma 3.7; Lemma 3.8; Equation 8; Proof of Theorem 3.3.

The authors do not agree to the retraction of the Article.

\section{Reference}

1. Molontay, R. Networks and fractals. BSc thesis, Budapest University of Technology and Economics, http://math.bme.hu/ molontay/ Szakdolgozat.pdf (2013).

(c) (i) Open Access This article is licensed under a Creative Commons Attribution 4.0 International License, which permits use, sharing, adaptation, distribution and reproduction in any medium or format, as long as you give appropriate credit to the original author(s) and the source, provide a link to the Creative Commons license, and indicate if changes were made. The images or other third party material in this article are included in the article's Creative Commons license, unless indicated otherwise in a credit line to the material. If material is not included in the article's Creative Commons license and your intended use is not permitted by statutory regulation or exceeds the permitted use, you will need to obtain permission directly from the copyright holder. To view a copy of this license, visit http://creativecommons.org/licenses/by/4.0/.

(C) The Publisher 2020 